\title{
Author Correction: A re-examination of the projected subtropical precipitation decline
} Jie He and Brian J. Soden

Correction to: Nature Climate Change https://doi.org/10.1038/nclimate3157, published online 14 November 2016.

In the legend for the light blue bars in Fig. 4 of this Letter, there is an erroneous $\partial$ before the $q$; that is, it is written as $-\langle\nabla \cdot(\partial V \cdot \partial q)\rangle$ but should be $-\langle\nabla \cdot(\partial V \cdot q)\rangle$.

Published online: 13 August 2018

https://doi.org/10.1038/s41558-018-0265-z

\section{Author Correction: Climate-carbon cycle uncertainties and the Paris Agreement}

P. B. Holden (D), N. R. Edwards (D), A. Ridgwell (D), R. D. Wilkinson, K. Fraedrich, F. Lunkeit, H. Pollitt (D) J.-F. Mercure (D),

P. Salas (D), A. Lam, F. Knobloch (D), U. Chewpreecha and J. E. Viñuales

Correction to: Nature Climate Change https://doi.org/10.1038/s41558-018-0197-7, published online 25 June 2018.

In the version of this Article originally published, H. Pollit's name was incorrectly listed as H. E. Pollit (H.E.P.) throughout the paper, this has been corrected to H. Pollitt (H.P.) in the online versions of this Article.

Published online: 4 July 2018

https://doi.org/10.1038/s41558-018-0235-5

\section{Author Correction: Achieving a climate justice pathway to $1.5^{\circ} \mathrm{C}$}

Mary Robinson and Tara Shine (D)

Correction to: Nature Climate Change https://doi.org/10.1038/s41558-018-0189-7, published online 29 June 2018.

In the version of this Perspective originally published, there was a typo in column 3 of Table 1: 'Wealth' should have read 'Health'. This has been corrected in the online versions of this Perspective.

Published online: 7 August 2018

https://doi.org/10.1038/s41558-018-0270-2 